\title{
A retrospective study on transabdominal ultrasound measurements of the rumen wall thickness to evaluate chronic rumen acidosis in beef cattle
}

\author{
Enrico Fiore ${ }^{1}$, Vanessa Faillace ${ }^{1 *}$ (D) Massimo Morgante ${ }^{1}$, Leonardo Armato $^{2}$ and Matteo Gianesella ${ }^{1}$
}

\begin{abstract}
Background: Chronic and subacute rumen acidosis are economically important in the beef industry. The aim of this study was to evaluate the potential suitability of the transabdominal ultrasonographic examination of the ruminal wall to diagnose chronic rumen acidosis in beef cattle compared to direct measurement of ruminal pH, as a fast non-invasive tool to be used in field condition. Ultrasonographic examination of the rumen was conducted in 478 beef cattle before rumenocentesis (chronic rumen acidosis group $=\mathrm{pH} \leq 5.8$; healthy group $=\mathrm{pH} \geq 5.9$ ). Rumen wall ultrasound measurements included rumen wall thickness (RWT) and rumen mucosa and submucosa thickness (RMST).

Results: The Analysis of Variance showed the high significant effect of the $\mathrm{pH}$ class for RWT and RMST $(P<0.001)$. Spearman RANK correlation analysis showed interaction between rumen $\mathrm{pH}$ and RWT $(-0.71 ; P<0.0001)$ and RMST $(-0.75 ; P<0.0001)$. A significant Spearman's correlations were found between volatile fatty acids (VFA) and RWT and RMST.

The differentiation efficiency of RWT between healthy and chronic rumen acidosis groups, as a result of the receiver operator curve (ROC) analysis, was quite good with an area under the receiver operator curve (AUROC) of 0.88: $P<$ $0.0001 ; 95 \%$ Cl: $0.83-0.98$. Using a cut-off value of $>8.2 \mathrm{~mm}$. The differentiation efficiency of RMST between healthy and chronic rumen acidosis groups, as a result of ROC curve analysis, was good with an AUROC of 0.90: $p<0.0001$; 95\% Cl: 0.85-0.94. Using a cut-off value of $>5.3 \mathrm{~mm}$.
\end{abstract}

Conclusions: In this study, the thickening of RWT and RMST is correlated with the changes of ruminal pH. Transabdominal rumen ultrasound has the potential to become a powerful diagnostic tool useful to identify fattening bulls affected by chronic rumen acidosis.

Keywords: Beef cattle, Chronic rumen acidosis, Rumen wall, Ultrasonography

\footnotetext{
* Correspondence: vanessa.faillace@unipd.it

'Department of Animal Medicine, Productions and Health (MAPS), University

of Padua, Viale dell'Università 16, 35020 Legnaro (PD), Italy

Full list of author information is available at the end of the article
}

(c) The Author(s). 2020 Open Access This article is licensed under a Creative Commons Attribution 4.0 International License, which permits use, sharing, adaptation, distribution and reproduction in any medium or format, as long as you give appropriate credit to the original author(s) and the source, provide a link to the Creative Commons licence, and indicate if changes were made. The images or other third party material in this article are included in the article's Creative Commons licence, unless indicated otherwise in a credit line to the material. If material is not included in the article's Creative Commons licence and your intended use is not permitted by statutory regulation or exceeds the permitted use, you will need to obtain permission directly from the copyright holder. To view a copy of this licence, visit http://creativecommons.org/licenses/by/4.0/. The Creative Commons Public Domain Dedication waiver (http://creativecommons.org/publicdomain/zero/1.0/) applies to the data made available in this article, unless otherwise stated in a credit line to the data. 


\section{Background}

In the livestock breeding of beef cattle, the intensive production system is commonly used in Italy. This farming method includes often the importation of beef cattle from northern Europe at the age of 8-15 months and taken to the finishing stage and slaughter [1]. A critical phase is the restocking period after transportation and the first 20 to 30 days following housing $[1,2]$. The growth of animals is subject to many stressors (different conditions of temperature, humidity, environment, transport, the change from an acclimation diet rich in fiber to a growth diet rich in concentrate, social interactions, and diseases), which change the physiological homeostasis and compromise the health status in restocking phase [2].

High-concentrate diets can cause metabolic disorders such as rumen acidosis [3] and bloat [4]. Ruminal acidosis is the most common condition caused precisely by high intake of grains rich in starch and low consumption of physically effective fiber [3]. These factors result in increased yields of VFA and lactic acid in the rumen. In addition, the low diet in long fiber decreases the time in the chewing and the relative saliva production is lower than normal. The negative effect on the rumen $\mathrm{pH}$ is because of the inadequate saliva production needed to neutralize the acids [5, 6]. High-concentrate diets can lead to increased rumen papillae length and width in response to changes in VFA concentration and ruminal fluid $\mathrm{pH}$ [7].

The ruminal acidosis could be defined as a digestive tract disorder that negatively affects ruminal fermentation, animal health, production and corporate profit [8]. Acidosis of ruminants often is separated into several forms, including acute, chronic or subacute ruminal acidosis [9]. The diagnosis of subacute ruminal acidosis is difficult under farm conditions as clinical signs are commonly subtle and delayed after the time of the acidotic insult [10].

Ruminal $\mathrm{pH}$ is the most commonly used parameter for detecting, and it can be analyzed with different methods. The most useful cut-off point between normal and abnormal has been defined as $\mathrm{pH} \leq 5.5$ [11]. A ruminal $\mathrm{pH}$ $<5.8$ is referred to as indicating a critical $\mathrm{pH}$-situation on a farm and it suggests a serious situation developing problem of subacute rumen acidosis [5, 9].

There are two principal methods to collect fluid samples: by an oral tube or by percutaneous rumenocentesis. Rumenocentesis is considered the golden test to perform the diagnosis of subacute rumen acidosis $[5,12]$ as it avoids contamination of the ruminal fluid by saliva (basic $\mathrm{pH}$ ) which is ingested when the oral probe passes through the oral cavity and esophagus [13]. More studies considered rumenocentesis as an invasive and notroutine procedure with severe complications [14].
Although other recent studies have used this technique without significant welfare concerns or adverse effects on health and production in dairy cattle $[15,16]$, it is not yet used and implemented in beef cattle [1].

In recent years, ultrasonography has applied widely available in daily food animal practice. It is an ideal diagnostic tool for the investigation of bovine gastrointestinal disorders and it is commonly used in farm animals $[17,18]$.

Previous studies have suggested the transabdominal ultrasound approach of the rumen as a possible diagnostic tool for subacute rumen acidosis in dairy cattle. The wall of the rumen could be identified as a thick echogenic line $(3.0-4.8 \mathrm{~mm}$ ) adjacent to the left abdominal wall from the left flank of dairy cows [19]. MirmazhariAnwar et al. (2013) [20] reported increasing rumen mucosa thickness when using a transabdominal rumen ultrasound in cannulated bulls fed diets, increasing in concentrate level from 5 to $96 \%$ dry matter (DM). Neubauer et al. (2018) [21] confirmed the potential of rumen mucosa thickness measurement via ultrasound as a diagnostic tool for subacute rumen acidosis, adjusted for the age or lactation number of the individual dairy cow.

Therefore, the aim of this study was to evaluate the potential suitability of the transabdominal ultrasonographic examination of the ruminal wall to diagnose of chronic rumen acidosis in beef cattle, as a fast a noninvasive tool to be used in field condition, compared to direct measurement of ruminal $\mathrm{pH}$.

\section{Results}

Data showed after $15 \pm 5$ days of the housing that two hundred eighty-nine fattening bulls (60.5\%) had a rumen $\mathrm{pH}>5.9$, while one hundred eighty-nine (39.5\%) had a rumen $\mathrm{pH}<5.9$ and respectively one hundred forty-eight (30.9\%) in chronic rumen acidosis $(5.5<\mathrm{pH} \geq 5.8)$ and forty-one $(8.5 \%)$ in the risk of acute rumen acidosis $(\mathrm{pH}<5.5)[9,16]$.

Table 1 showed the values regarding the descriptive analysis of the results found for the rumen $\mathrm{pH}$, RWT, RMST and VFA (acetic acid, propionic acid, butyric acid).

The Analysis of Variance (ANOVA) model showed that there was the high significant effect of the $\mathrm{pH}$ class for RWT and RMST $(\mathrm{P}<0.001)$ and the equate significant effect of rumen muscularis and serosa $(P=0.014)$. For RWT and RMST poc-hoc pairwise comparisons among levels showed that normal class was statistically different from the other two (chronic rumen acidosis and risk of acute rumen acidosis). Based on these results, animals were grouped as healthy (normal class) and chronic rumen acidosis (chronic rumen acidosis and risk of acute rumen acidosis class). 
Table 1 Descriptive data (mean, standard deviation, minimum and maximum value, median, 5th, and 95th percentile) regarding the rumen $\mathrm{pH}$, the ultrasonographic measurements of RWT and RMST and VFA (acetic acid, propionic acid, butyric acid)

\begin{tabular}{|c|c|c|c|c|c|c|}
\hline \multirow[b]{3}{*}{ Parameters } & \multicolumn{6}{|c|}{ Total Population $(n=478)$} \\
\hline & \multirow[b]{2}{*}{ Mean } & \multirow[b]{2}{*}{ SD } & \multirow[b]{2}{*}{ Minimum-Maximum value } & \multirow[b]{2}{*}{ Median } & \multicolumn{2}{|c|}{ Percentiles } \\
\hline & & & & & 5th & 95th \\
\hline Rumen pH & 6 & 0.4 & $4.6-7.2$ & 6 & 5.7 & 6.3 \\
\hline Rumen wall thickness (mm) & 8.1 & 2.2 & $4.7-16.1$ & 7.7 & 6.3 & 9.5 \\
\hline Rumen mucosa and submucosa thickness (mm) & 5.7 & 1.8 & $2.9-11.4$ & 5 & 4.2 & 7 \\
\hline Acetic Acid (mg/ml) & 3.1 & 0.5 & $0.9-4.4$ & 3.1 & 2.7 & 3.5 \\
\hline Propionic acid (mg/ml) & 1.3 & 0.3 & $0.3-2.5$ & 1.2 & 1.1 & 1.5 \\
\hline Butyric Acid (mg/ml) & 0.9 & 0.2 & $0.1-1.7$ & 0.9 & 0.8 & 1.1 \\
\hline
\end{tabular}

Spearman RANK correlation analysis showed interaction between rumen $\mathrm{pH}$ and RWT $(-0.71 ; P<0.0001)$ and RMST $(-0.75 ; \mathrm{P}<0.0001)$. A significant Spearman's correlations (Table 2) were found between VFA, RWT and RMST.

The differentiation efficiency of RWT between healthy and chronic rumen acidosis groups, as a result of the receiver operator curve (ROC) analysis, was quite good with an area under the receiver operator curve (AUROC) of 0.88: $P<0.0001$; 95\% CI: 0.83-0.98. Using a cut-off value of $>8.2 \mathrm{~mm}$, calculated by Youden index, sensitivity was $90 \%$ and specificity was $79 \%$, positive likelihood ratio $=4.34$, negative likelihood ratio $=0.13$ (Fig. 1).

The differentiation efficiency of RMST between healthy and chronic rumen acidosis groups, as a result of ROC curve analysis, was good with an AUROC of 0.90: $p<0.0001$; 95\% CI: 0.85-0.94. Using a cut-off value

Table 2 Spearman's Correlation ( $r$ values) and statistical significance ( $P$ values) between parameters investigated

\begin{tabular}{lll}
\hline Parameters & $\mathbf{r}$ & $\mathbf{P}$ \\
\hline Rumen wall thickness & -0.71 & $<0.0001$ \\
Rumen pH & 0.37 & $<0.0001$ \\
Acetic acid & 0.46 & $<0.0001$ \\
Propionic acid & 0.39 & $<0.0001$ \\
Butyric acid & 0.94 & $<0.0001$ \\
Rumen mucosa and submucosa thickness & & \\
Rumen mucosa and submucosa thickness & -0.75 & $<0.0001$ \\
Rumen pH & 0.30 & 0.005 \\
Acetic acid & 0.47 & $<0.0001$ \\
Propionic acid & 0.34 & $<0.0001$ \\
Butyric acid & & \\
Rumen pH & -0.50 & $<0.0001$ \\
Acetic acid & -0.66 & 0.001 \\
Propionic acid & -0.44 & $<0.0001$ \\
Butyric acid & &
\end{tabular}

of $>5.3 \mathrm{~mm}$, calculated by Youden index, sensitivity was $93 \%$ and specificity was $76 \%$, positive likelihood ratio $=$ 3.96, negative likelihood ratio $=0.08$ (Fig. 2).

\section{Discussion}

The results of our study show that transabdominal ultrasound measurements of the rumen wall thickness represent a useful tool and a potentially suitable method to diagnose chronic rumen acidosis in beef cattle. Ruminal acidosis continues to be a common ruminal digestive disorder in beef cattle and can lead to marked reductions in cattle performance [9]. Our first result showed the effect of the increase dietary concentrate during the receiving period in fattening cycle. The $39.5 \%$ of all animals included in the study had a rumen $\mathrm{pH}$ lower than the threshold value of 5.8 after $15 \pm 5$ days of the housing.

The decrement of the $\mathrm{pH}$ value may be attributed to the sudden change of the diet and to the consequential lack of adaptive capability of the bulls. Diets with highconcentrate content leading to a moderate decline in ruminal fluid $\mathrm{pH}$ were consistently reported to trigger an increase in length of ruminal papillae, dilatation and hyperemia of mucosal and submucosal capillaries as well as submucosal edema, thereby causing a marked increase in thickness of ruminal mucosa. Therefore, the thickening of the rumen mucosa was well correlated with the decrement of rumen $\mathrm{pH}[7,22]$.

In our study, the higher correlation between ruminal $\mathrm{pH}$ and RMST could largely explain this $(\mathrm{r}=0.75, P<$ 0.0001). According to Mirmazhari-Anwar et al. (2013) [20] found also a higher correlation between ruminal $\mathrm{pH}$ and rumen mucosa thickness $(r=0.818, P<0.01)$ in adult dairy bulls fed diets varying in concentrate levels from $5 \%$ up to $96 \%$, which consequently led to a more extreme range in ruminal $\mathrm{pH}$ (5.2-7.1). Moreover, in this study RWT and RMST had a significant correlation to VFA determinate: acetic acid, propionic acid, butyric acid. This is explained by increased concentrations of VFA in the rumen that are primarily stimulants for 


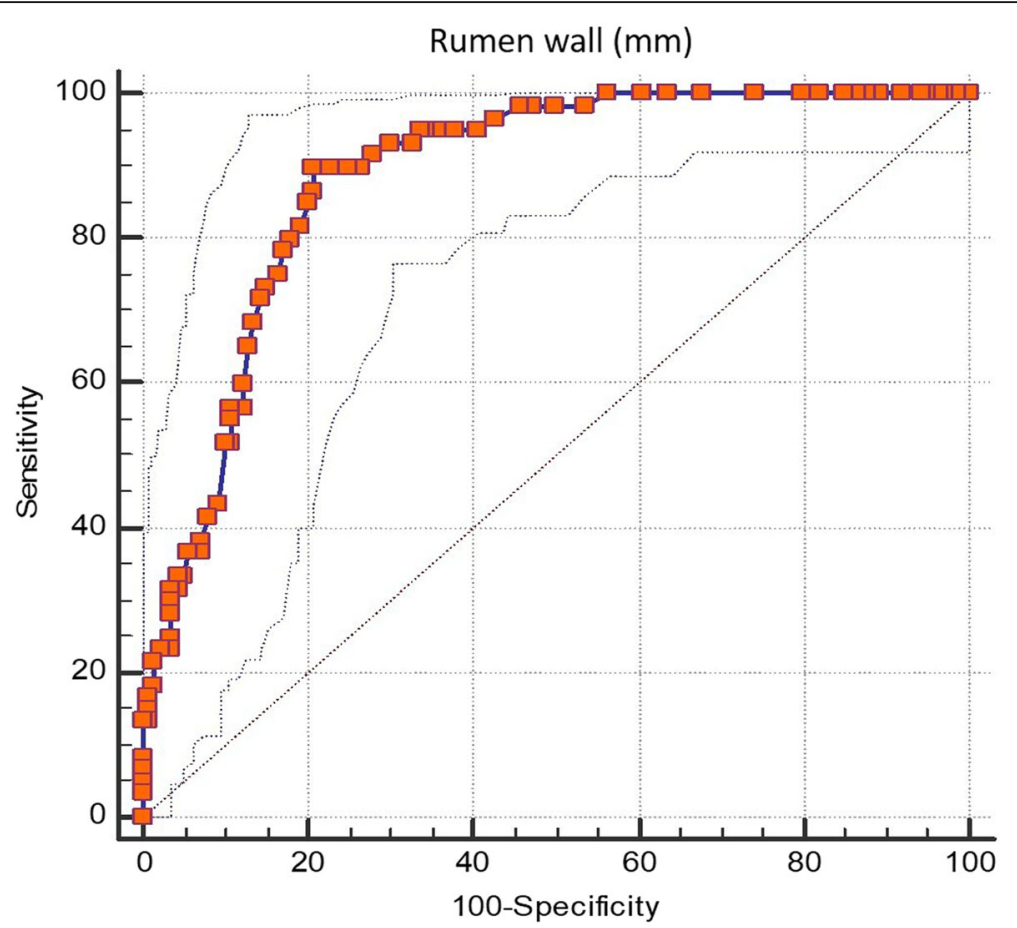

Fig. 1 Receiver operating characteristic (ROC) curve analysis of the rumen wall thickness for detecting chronic acidosis. The best cut-off value is $>8.2 \mathrm{~mm}$, (area under the ROC curve of 0.88: $P<0.0001 ; 95 \%$ c.i. 0.83 to 0.98 ; sensitivity $90 \%$; specificity $79 \%$; positive likelihood ratio 4.34; negative likelihood ratio 0.13). criterion: Youden index

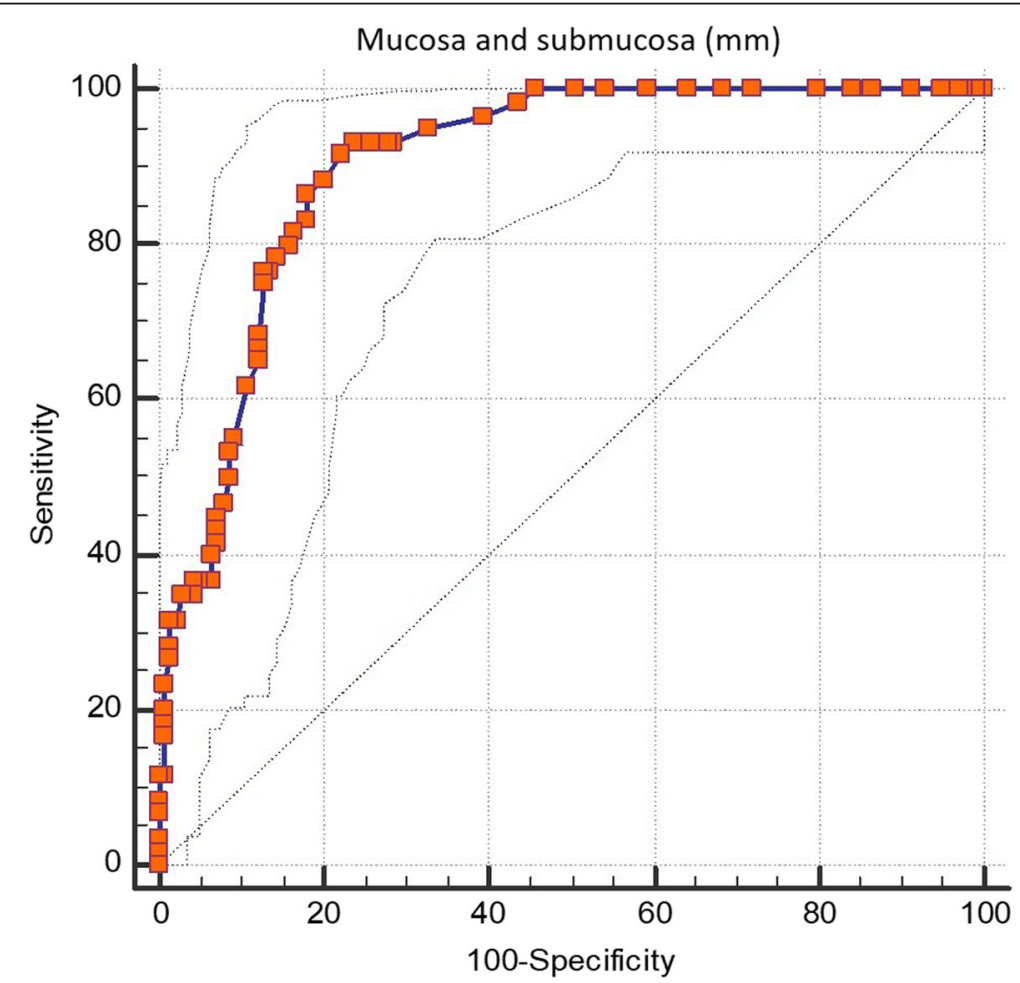

Fig. 2 Receiver operating characteristic (ROC) curve analysis of the mucosa and submucosa thickness for detecting chronic acidosis. The best cutoff value is $>5.3 \mathrm{~mm}$, (area under the ROC curve of 0.90: P<0.0001; 95\% c.i. 0.85 to 0.94; sensitivity 93\%; specificity $76 \%$; positive likelihood ratio 3.96; negative likelihood ratio 0.08). criterion: Youden index 
papillary development [23, 24]. The VFA were accepted to be the main trigger for growth of rumen papillae wherever the mucosa was directly exposed to these acids [23, 24]. The adaptation of morphological dimensions of ruminal epithelia could be functionally fast and strong, because the epithelia has to cope with the rapid increase in VFA load to which they are exposed [25, 26]. Furthermore, recent studies suggested that an increase in ruminal VFA and dietary particle sizes can alter expression of genes (like Insulin-like growth factor-binding proteins) involved in cell proliferation/apoptosis process involved in the adaptation of the rumen epithelium [25, 27]. The higher production of VFA, particularly butyrate and propionate, and a higher absorption from the rumen by the mucosa, in a low ruminal $\mathrm{pH}$, will lead to a parakeratosis of the ruminal epithelium that consequently can cause a rumenitis. Rumenitis is a frequent sequel to rumen acidosis $[25,28]$.

Mirmazhari- Anwar et al. (2013) [20] determined a cut-off value of $7.3 \mathrm{~mm}$ for the rumen mucosa thickness to identify animals with ruminal fluid $\mathrm{pH}<5.5$ approximately $4 \mathrm{~h}$ post feeding. This cut-off value was obtained to measurements of rumen mucosa thickness by $8 \mathrm{MHz}$ linear transducer in five cannulated bulls fed diets, increasing in concentrate level (5-96\% DM).

Our study included four hundred seventy-eight beef cattle and cut-offs of $>5.4 \mathrm{~mm}$ and $>8.2 \mathrm{~mm}$ for RMST and RWT, respectively, were determined for distinguishing animals with ruminal $\mathrm{pH} \leq 5.8$.

However, this study has methodological limitations. First, the research was limited because we used a retrospective study design, adherence to a coherent standardized protocol to get repeatability of ultrasound measurements was not possible, although the high number of the ultrasound evaluation performed by a single observer with the same portable ultrasound scanner. Second, the limited axial resolution $0.3 \mathrm{~mm}$ of a $6.6 \mathrm{MHz}$ probe was used in the study that limits the smallest detectable difference in thickness. Thus, evaluation of RWT and RMST with higher frequency probes that have higher axial resolution with more accurate measurement it could lead to more reliable results.

Further studies will be necessary to evaluate whether RWT and RMST could reach a plateau at a certain time or a ratio of concentrate feeding and to what extent diminished cell function and parakeratosis occurs as hypothesized by Neubauer et al. (2018) [21].

Although the sample of the animals in the study was considerable, we had investigated just beef cattle of the same sex, breed and stage of breeding, other several variables should be considered seeing if there are differences in RWT and RMST measurements like in dairy cows [21].

\section{Conclusions}

Diagnostic ultrasound is a useful tool if employed correctly, enabling non-invasive and potentially rapid evaluation of areas of interest. Transabdominal ultrasonography of the RWT and RMST has established its potential to be a suitable diagnostic tool, fast, non-invasive and easily applicable to be used in field condition to identify beef cattle affected by chronic rumen acidosis.

\section{Methods}

This retrospective study was carried out from historical clinical records of the Ruminant Clinic of the Padua University Veterinary Teaching Hospital and as part of doctoral studies.

We performed this retrospective study from a dataset recorded from the extramural clinical activity of the Preventive Medicine Service and Breeding of Ruminants Clinic (Veterinary Teaching Hospital, University of Padua - OVUD) from 2013 to 2017. The reasons for a retrospective study rather than prospective, is a lack of existing literature on the topic of beef cattle, low expensive methods and simplicity.

From a dataset of 1389 animals (37 beef cattle farms) assessed by rumenocentesis and ruminal wall ultrasound on the clinical examination, 478 beef cattle were selected based on the following inclusion criteria: sex, breed and stage of breeding.

The animals were young fattening bulls of Charolaise breed, imported from France with an average body weight of $424.5 \pm 33.4 \mathrm{~kg}$ and an average age of $10.8 \pm$ 0.7 months at $15 \pm 5$ days after housing. The arriving cattle were fed a high long fiber acclimation diet for 5-7 days before moving on to the growth diet. After that period, all animals were fed with a finishing diet mainly based on maize (silage and high moisture ear), soya bean meal, dry sugar beets and wheat straw. The diet was provided daily as a total mixed ration (TMR) for ad libitum intake based on 10\% feed refusal (as-fed basis). Dry matter intake (DMI) mean values were recorded for all beef cattle farms (mean values: DMI: $18.0 \pm 1.5 \mathrm{Kg}$ per animal; DM: $9.78 \pm 0.8$ per animal). Drinking water was available ad libitum, through two bowls per pen. All animals were housed in boxes of 10 in individual concretefloor tie stalls within an enclosed barn.

\section{Ultrasonography, rumenocentesis and evaluation of rumen fluid $\mathrm{pH}$}

The ultrasound and rumenocentesis evaluations were performed at $15 \pm 5$ days after housing. Animals were secured in standing position in a crate. 
The transtransabdominal ultrasound of the ruminal wall was performed with a portable ultrasound scanner (MyLabOne $^{\mathrm{Tm}}$, Esaote S.p.a.), equipped with a multifrequency convex probe (2.2-4.3-6.6 MHz; SC3421, Esaote S.p.a.). All ultrasonographic examinations were performed by the same operator.

Ultrasonographic images were taken on the left side, from the ventral sac of the rumen, approximately 15-20 $\mathrm{cm}$ caudal and ventral to the costocondral junction of the last rib, the same rumenocentesis area [16]. Ultrasonographic examination of the rumen wall was conducted $5 \mathrm{~min}$ before the rumenocentesis. The examination window was clipped and cleaned with alcohol, and lubrication gel was applied to ensure the examination position and proper conduction.

Ultrasonographic settings were maintained constant throughout the all scans: frequency $6.6 \mathrm{MHz}$, depth 8.0 $\mathrm{cm}$, gain $90.0 \%$, time gain compensation was in a neutral position.

Ultrasound image was taken when the ruminal wall rested against the abdominal wall in a relaxed state at the end of the ruminal contraction and the probe marker was orientated towards the patient's head.

Measurements were obtained from a single image of the rumen. RWT and RMST were measured using the distance measurement function of the software MyLab ${ }^{\mathrm{Tm}}$ Desk (Esaote) (Fig. 3). The rumen wall has a characteristic appearance of three distinct sonographic layers: starting at the inner surface of the rumen the first hyperechoic layer corresponds to the mucosa and submucosa (the two layers cannot be distinguished one from the other), the second hypoechoic layer is the muscularis and the third hyperechoic layer corresponds to the serosa $[20,21]$.

A sample of rumen fluid was taken from each animal by the rumenocentesis method as described by Nordlund and Garrett (1994) [11] and modified by Gianesella et al. (2010) [16]. Samples of rumen fluid were collected between 4 and $6 \mathrm{~h}$ after TMR administration because during this interval the rumen $\mathrm{pH}$ reaches the peak of acidity [6, 29]. From each animal was collected $15 \mathrm{ml}$ of rumen fluid and its $\mathrm{pH}$ was determined using a digital portable $\mathrm{pH}$ meter (Zetalab PC70, XSinstruments, Padova, Italy).

The VFA were determined using an aliquot of $8 \mathrm{ml}$ of ruminal liquid which was immediately acidified with 2 $\mathrm{mL}$ of hydrogen chloride $(\mathrm{HCl} 0.6 \mathrm{M})$ and stored at $4{ }^{\circ} \mathrm{C}$ until the samples arrived at the laboratory where they were stored at $-20{ }^{\circ} \mathrm{C}$ until analysis.

The VFA contents were measured on the supernatant of the rumen fluid samples obtained by centrifugation (1300 × gfor 15 min) using an HPLC Perkin Elmer Series 10 , mobile phase $\mathrm{H} 2 \mathrm{SO} 40.0025 \mathrm{~N}$, flux $0.6 \mathrm{~mL} / \mathrm{min}$, detector Waters 410, column Gecko 2000 at a working temperature of $60^{\circ} \mathrm{C}$ [5]. VFA were determined: acetic acid, propionic acid, butyric acid.

\section{Statistical analysis}

All statistical analyses were performed using SAS (SAS 9.3, Institute Inc., Cary, NC).

Ultrasound measurements were submitted to One-Way Analysis of Variance (ANOVA) (PROC GLM) considering the effect of the $\mathrm{pH}$ class (normal vs chronic rumen acidosis vs risk of acute rumen acidosis: normal $>5.9$; chronic rumen acidosis between 5.5-5.8; risk of acute rumen acidosis <5.5). All pairwise contrast between least squares means were performed using the Bonferroni correction. Normality of residuals was evaluated by Shapiro-Wilk test (PROC UNIVARIATE) and values $\geq 0.9$ were considered as normal. Based on the results of ANOVA, animals were grouped as healthy and chronic rumen acidosis.

Spearman RANK correlation analysis between ultrasound measurements and the rumen fluid parameters were calculated.

ROC curve analysis (MedCalc) was performed to calculate on ultrasound measurements the threshold that discriminates healthy vs chronic rumen acidosis groups.

The threshold was identified using the Youden criterion. The area under the ROC curve (AUROC) as taken as an index of accuracy.

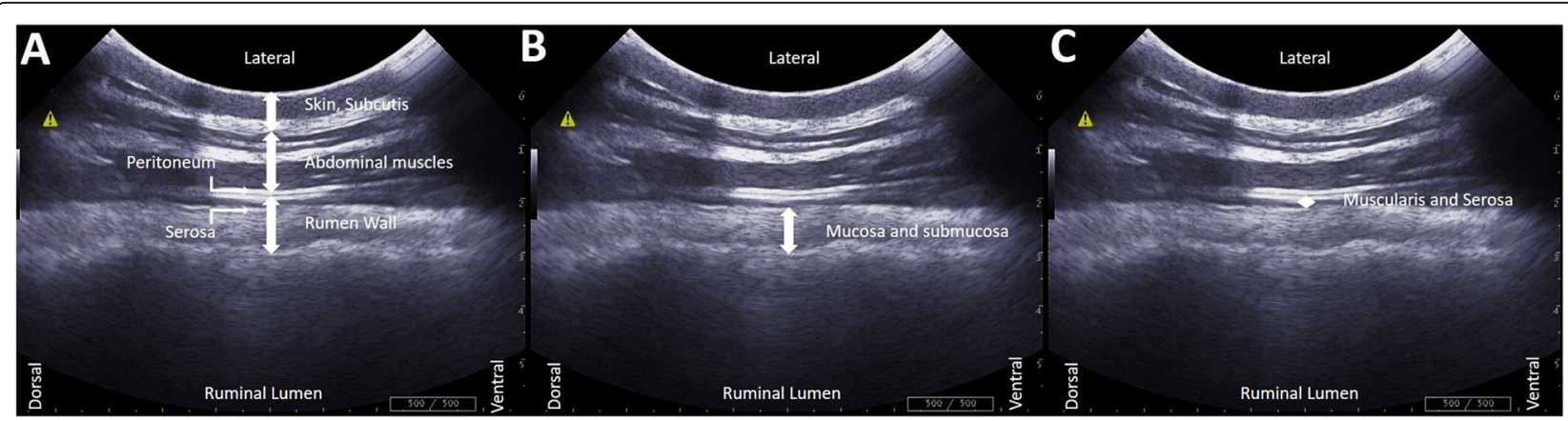

Fig. 3 Ultrasonographic image of the abdominal and rumen wall from the left flank showing (a) from top to bottom skin and subcutis, abdominal muscles, peritoneum, serosa and rumen wall (b) mucosa and submucosa of the rumen (c) muscolaris and serosa of the rumen 


\section{Abbreviations}

AUROC: Area under the receiver operator curve; DM: Dry matter; DMI: Dry matter intake; RMST: Rumen mucosa and submucosa thickness; ROC: Receiver operating characteristic; RWT: Rumen wall thickness; SD: Standard deviation; TMR: Total mixed ration; VFA: Volatile fatty acids

\section{Acknowledgements}

Not applicable.

\section{Authors' contributions}

EF designed the experiment and performed the experiments. LA helped with the experiments. EF, VF, MG, MM interpreted the data. EF, VF wrote the first draft of the manuscript. LA, MG and MM were participated in revision of the manuscript. All authors read, reviewed, and approved the final manuscript.

\section{Funding}

Not applicable.

\section{Availability of data and materials}

The datasets used and/or analysed during the current study are available from the corresponding author on reasonable request.

\section{Ethics approval and consent to participate}

Collection of samples of rumen fluid and ultrasound examinations from beef cattle was conducted during clinical investigations with the written consent of the animals' owner during the routinely clinical activity of the Ruminant Clinic of the Padua University Veterinary Teaching Hospital, University of Padua. In accordance with the European Parliament and Council normative 2010/63/UE (22nd September 2010) on the protection of animals used for scientific purposes and with the National Guidelines of Italian Ministry of Health for the care and use of animals (D.L. 4 March 2014 n. 26 and D.L. 27 January $1992 \mathrm{n} .116$ ) the non-experimental clinical veterinary practice is excluded from the scope of legislation and therefore ethical approval was not required for this study.

\section{Consent for publication}

Not applicable.

\section{Competing interests}

The authors declare that they have no competing interests.

\section{Author details}

'Department of Animal Medicine, Productions and Health (MAPS), University of Padua, Viale dell'Università 16, 35020 Legnaro (PD), Italy. ${ }^{2}$ Veterinary Freelance, Viale dell'Università 16, 35020 Legnaro (PD), Italy.

Received: 22 January 2020 Accepted: 8 September 2020 Published online: 15 September 2020

\section{References}

1. Fiore E, Armato L, Morgante M, Muraro M, Boso M, Gianesella M. Methaphylactic effect of tulathromycin treatment on rumen fluid parameters in feedlot beef cattle. Can J Vet Res. 2016;80(1):60-5.

2. Stanton AL, Kelton DF, Leblanc SJ, Millman ST, Wormuth J, Dingwell RT, et al. The effect of treatment with long-acting antibiotic at postweaning movement on respiratory disease and on growth in commercial dairy calves. J Dairy Sci. 2010;93(2):574-81. https://doi.org/10.3168/jds.2009-2414.

3. Owens FN, Secrist DS, Hill WJ, Gill DR. Acidosis in cattle: a review. J Anim Sci. 1998;76(1):275-86. https://doi.org/10.2527/1998.761275x.

4. Cheng KJ, McAllister TA, Popp JD, Hristov AN, Mir Z, Shin HT. A review of bloat in feedlot cattle. J Anim Sci. 1998;76(1):299-308,

5. Morgante M, Stelletta C, Berzaghi P, Gianesella M, Andrighetto I. Subacute rumen acidosis in lactating cows: an investigation in intensive Italian dairy herds. J Anim Physiol Anim Nutr (Berl). 2007;91(5-6):226-34. https://doi.org/ 10.1111/j.1439-0396.2007.00696.x.

6. Dijkstra J, Ellis J, Kebreab E, Strathe A, Lopez S, France J, et al. Ruminal pH regulation and nutritional consequences of low pH. Anim Feed Sci Tech. 2012;172(1-2):22-33. https://doi.org/10.1016/j.anifeedsci.2011.12.005.

7. Cernik J, Stercova E Sterc J, Fictum P, Lunacek J, Halouzka R. The effect of intensive fattening of bulls with a high-concentrate diet on ruminal mucosa
- a morphometric study. Acta Vet Brno. 2011;80(3):275-9. https://doi.org/10. 2754/avb201180030275.

8. Krause $\mathrm{K}$, Oetzel G. Inducing subacute ruminal acidosis in lactating dairy cows. J Dairy Sci. 2005;88(10):3633-9. https://doi.org/10.3168/jds.S00220302(05)73048-4.

9. Nagaraja T, Titgemeyer E. Ruminal acidosis in beef cattle: the current microbiological and nutritional outlook. J Dairy Sci. 2007;90:E17-38. https:// doi.org/10.3168/jds.2006-478.

10. Humer E, Aschenbach J, Neubauer V, Kroger I, Khiaosa-ard R, Baumgartner W, et al. Signals for identifying cows at risk of subacute ruminal acidosis in dairy veterinary practice. J Anim Physiol Ann. 2018;102(2):380-92. https://doi. org/10.1111/jpn.12850.

11. Nordlund K, Garrett EF. Rumenocentesis: a technique for collecting rumen fluid for the diagnosis of subacute rumen acidosis in dairy herds. Bovine Practitioner. 1994:28:109-12.

12. O'Grady L, Doherty ML, Mulligan FJ. Subacute ruminal acidosis (SARA) in grazing Irish dairy cows. Vet J. 2008;176(1):44-9. https://doi.org/10.1016/j.tvjl. 2007.12.017

13. Nordlund K, Garrett E, Oetzel G. Herd-based Rumenocentesis - a clinical approach to the diagnosis of subacute rumen acidosis. Compend Contin Educ Pract Vet. 1995:17(8):S48-56.

14. Strabel D, Ewy A, Kaufmann T, Steiner A, Kirchhofer M. Rumenocentesis: a suitable technique for analysis of rumen juice $\mathrm{pH}$ in cattle? Schweiz Arch Tierheilkd. 2007;149(7):301-6.

15. Kleen J, Hooijer G, Rehage J, Noordhuizen J. Subacute ruminal acidosis in Dutch dairy herds. Vet Rec. 2009;164(22):681-4. https://doi.org/10.1136/vr. 164.22.681.

16. Gianesella M, Morgante M, Cannizzo C, Stefani A, Dalvit P, Messina V, et al Subacute ruminal acidosis and evaluation of blood gas analysis in dairy cow. Vet Med Int. 2010;2010:392371. https://doi.org/10.4061/2010/392371.

17. Braun U, Schweizer A, Trosch L. Ultrasonography of the rumen of dairy cows. BMC Vet Res. 2013:9:44. https://doi.org/10.1186/1746-6148-9-44.

18. Banzato T, Fiore E, Morgante M, Manuali E, Zotti A. Texture analysis of Bmode ultrasound images to stage hepatic lipidosis in the dairy cow: methodological study. Res Vet Sci. 2016;108:71-5. https://doi.org/10.1016/j. rvsc. 2016.08.007.

19. Imran S, Kumar A, Tyagi SP, Sharma S. Ultrasonographic examination of the rumen in healthy cows. Vet Med Int. 2011;2011:840629. https://doi.org/10. 4061/2011/840629.

20. Mirmazhari-Anwar V, Sharifi K, Mirshahi A, Mohri M, Grunberg W. Transabdominal ultrasonography of the ruminal mucosa as a tool to diagnose subacute ruminal acidosis in adult dairy bulls: a pilot study. Vet Q. 2013;33(3):139-47. https://doi.org/10.1080/01652176.2013.854942.

21. Neubauer V, Humer E, Kroger I, Meissl A, Reisinger N, Zebeli Q. Changes in rumen mucosa thickness measured by transabdominal ultrasound as a noninvasive method to diagnose subacute rumen acidosis in dairy cows. J Dairy Sci. 2018;101(3):2650-4. https://doi.org/10.3168/jds.2017-13682.

22. Dirksen G, Liebich HG, Brosi G, Hagemeister H, Mayer E. Morphology of the rumen mucosa and fatty acid absorption in cattle--important factors for health and production. Zentralbl Veterinarmed A. 1984;31(6):414-30.

23. Clauss M, Hofmann RR, Fickel J, Streich WJ, Hummel J. The intraruminal papillation gradient in wild ruminants of different feeding types: implications for rumen physiology. J Morphol. 2009;270(8):929-42. https:// doi.org/10.1002/jmor.10729.

24. Malhi M, Gui H, Yao L, Aschenbach JR, Gäbel G, Shen Z. Increased papillae growth and enhanced short-chain fatty acid absorption in the rumen of goats are associated with transient increases in cyclin D1 expression after ruminal butyrate infusion. J Dairy Sci. 2013;96(12):7603-16.

25. Steele MA, Schiestel C, AlZahal O, Dionissopoulos L, Laarman AH, Matthews JC, et al. The periparturient period is associated with structural and transcriptomic adaptations of rumen papillae in dairy cattle. J Dairy Sci. 2015;98(4):2583-95. https://doi.org/10.3168/jds.2011-4465.

26. Bannink A, France J, Lopez S, Gerrits W, Kebreab E, Tamminga S, et al. Modelling the implications of feeding strategy on rumen fermentation and functioning of the rumen wall. Anim Feed Sci Tech. 2008;143(1-4):3-26. https://doi.org/10.1016/j.anifeedsci.2007.05.002.

27. Wang B, Wang D, Wu X, Cai J, Liu M, Huang X, et al. Effects of dietary physical or nutritional factors on morphology of rumen papillae and transcriptome changes in lactating dairy cows based on three different forage-based diets. BMC Genomics. 2017:18:353. https://doi.org/10.1186/ s12864-017-3726-2. 
28. Enemark JM. The monitoring, prevention and treatment of sub-acute ruminal acidosis (SARA): a review. Vet J. 2008;176(1):32-43. https://doi.org/ 10.1016/j.tvj.2007.12.021.

29. Garrett EF, Pereira MN, Nordlund KV, Armentano LE, Goodger WJ, Oetzel GR.

Diagnostic methods for the detection of subacute ruminal acidosis in dairy cows. J Dairy Sci. 1999;82(6):1170-8. https://doi.org/10.3168/jds.S00220302(99)75340-3.

\section{Publisher's Note}

Springer Nature remains neutral with regard to jurisdictional claims in published maps and institutional affiliations.

Ready to submit your research? Choose BMC and benefit from:

- fast, convenient online submission

- thorough peer review by experienced researchers in your field

- rapid publication on acceptance

- support for research data, including large and complex data types

- gold Open Access which fosters wider collaboration and increased citations

- maximum visibility for your research: over $100 \mathrm{M}$ website views per year

At $\mathrm{BMC}$, research is always in progress.

Learn more biomedcentral.com/submissions 